\title{
A Bibliometric Analysis of Symmetry (2009-2019)
}

\author{
$\mathrm{Bo} \mathrm{Li}^{1}$, Zeshui Xu ${ }^{2, *}$, Edmundas Kazimieras Zavadskas ${ }^{3, * \mathbb{C}}$, Jurgita Antuchevičienè ${ }^{4}$ (]) \\ and Zenonas Turskis ${ }^{5}$ (i) \\ 1 Institute for Disaster Management and Reconstruction, Sichuan University, Chengdu 610207, China; \\ libo_0206@stu.scu.edu.cn \\ 2 Business School, Sichuan University, Chengdu 610064, China \\ 3 Department of Construction Management and Real Estate, Institute of Sustainable Construction, \\ Vilnius Gediminas Technical University, LT-10223 Vilnius, Saulètekio al. 11, Lithuania \\ 4 Department of Construction Management and Real Estate, Vilnius Gediminas Technical University, \\ LT-10223 Vilnius, Sauletekio al. 11, Lithuania; jurgita.antucheviciene@vgtu.lt \\ 5 Institute of Sustainable Construction, Vilnius Gediminas Technical University, LT-10223 Vilnius, \\ Sauletekio al. 11, Lithuania; zenonas.turskis@vgtu.lt \\ * Correspondence: xuzeshui@263.net (Z.X.); edmundas.zavadskas@vgtu.lt (E.K.Z.)
}

Received: 20 July 2020; Accepted: 29 July 2020; Published: 5 August 2020

\begin{abstract}
Symmetry is an international journal in the research fields of physics, chemistry, biology, mathematics, computer science, theory and methods, and other scientific disciplines and engineering. The first paper was published in 2009. Here, we make a bibliometric analysis of publications in Symmetry from 2009 to 2019. According to Web of Science (WoS), we obtained 3215 publications in this journal. First, we explore the publications, citation number, and citation structure based on bibliometric indicators. Second, we analyze the most influential objects, including countries/regions, institutions, authors, and papers. Cooperation networks are also presented. Next, the co-citation and burst detection analyses are conducted according to the techniques of visualization tools, i.e., VOSviewer and CiteSpace. Furthermore, the co-occurrence analyses and timeline view analyses of keywords are investigated, aiming to explore the research hotspots. Finally, this paper provides relatively thorough perspectives and reviews and discloses the future development trend of this journal and challenges for scholars, which will promote the development of the journal and in-depth research of scholars.
\end{abstract}

Keywords: Symmetry; bibliometric analysis; Web of Science; co-citation; burst detection analysis

\section{Introduction}

The bibliometric method has been widely applied in exploring publications' structure and the development of a journal. In recent years, scholars have systematically researched journals, such as European Journal of Operational Research [1], Technological and Economic Development of Economy [2], Information Sciences [3], IEEE Transactions on Fuzzy Systems [4], International Journal of Strategic Property Management [5], Journal of Civil Engineering and Management [6], and Baltic Journal of Road and Bridge Engineering [7]. The development trends of various research topics are also conducted, related to fuzzy decision making [8], sustainable energy [9], support vector machines [10], etc. Combining with visualization tools, i.e., VOSviewer [11,12], CiteSpace [13-15], CiteNetExplorer [16], Bicomb [17,18], BibExcel $[19,20]$, etc., the science mapping enriches the contents of bibliometric analyses from co-citation, co-occurrence, co-authorship, and burst detection aspects. It also helps scholars intuitively grasp research trends greatly and main research focuses in different phases [21]. In this paper, VOSviewer and CiteSpace are used to demonstrate the characteristics of the journal. The former conducts the co-citation analysis, co-authorship analysis, and co-occurrence analysis, aiming to present the structure 
of publications. The latter is chosen to cluster keywords and track development trends in different years of the journal by cluster analysis, burst detection analysis, and timeline analysis.

Symmetry is an international open-access journal indexed by the Science Citation Index Expanded (Web of Science, search for "Symmetry-Basel"), Scopus, MathSciNet (American Mathematical Society), and other databases with an impact factor of 2.645 by Journal Citation Reports (2019). It covers research on symmetry phenomena in scientific studies, including physics, chemistry, biology, mathematics, computer science, theory and method, etc. The details are listed as Table 1:

Table 1. The subject areas of Symmetry.

\begin{tabular}{|c|c|}
\hline Fields & Subject Areas \\
\hline Physics & $\begin{array}{l}\text { conservation laws, Noether's theorem, spatial parity, charge parity, time } \\
\text { parity, G-parity, standard model, internal symmetry, Lorentz symmetry, } \\
\text { transformations, invariance, conservation, local and global symmetries, } \\
\text { laws and symmetry, symmetry breaking, color symmetry, periodic and } \\
\text { quasiperiodic crystals, time-reversal symmetry breaking, symmetry and } \\
\text { complexity, Curie-Rosen symmetry principles, constants, biophysics, } \\
\text { entropy, and indistinguishability }\end{array}$ \\
\hline Chemistry & $\begin{array}{l}\text { crystal and crystallography; chiral molecules, chiral resolution and } \\
\text { asymmetric synthesis, asymmetric induction, chiral auxiliaries and } \\
\text { chiral catalysts, stereochemistry, diastereomers, stereogenic, } \\
\text { stereoisomers (enantiomers, atropisomers, diastereomers), stability, } \\
\text { mixing, and phase separation }\end{array}$ \\
\hline Biology & $\begin{array}{c}\text { symmetry in biology, radial symmetry (tetramerism, pentamerism, etc.), } \\
\text { diversity, preservation, sustainability, morphology, origin of life, and } \\
\text { molecular evolution (homochirality) }\end{array}$ \\
\hline Mathematics & $\begin{array}{l}\text { invariance, transformation, group theory, Lie groups, chirality, achiral or } \\
\text { amphichiral, helix and Möbius strip, knot theory, graph theory, isometry, } \\
\text { plane of symmetry, skewness, vertex algebra, asymmetry, dissymmetry, } \\
\text { nonsymmetry and antisymmetry, supergroups and nonlinear algebraic } \\
\text { structures, supersymmetry and supergravity, strings and branes, } \\
\text { integrability and geometry, information theory, Felix Klein's Erlangen } \\
\text { Program, and continuous symmetry }\end{array}$ \\
\hline $\begin{array}{l}\text { Computer Science, Theory and } \\
\text { Methods }\end{array}$ & $\begin{array}{l}\text { computer-aided design, computational geometry, computer graphics, } \\
\text { visualization, image compression, data compression, pattern } \\
\text { recognition, diversity, similarity, and conservation and sustainability }\end{array}$ \\
\hline
\end{tabular}

To date, Symmetry has published over 3000 documents with the development of 12 years. Therefore, it is valuable to explore the development trend based on bibliometric methods and science mapping. Since the first paper published in Symmetry in 2009, we analyze the journal from 2009 to 2019 mainly from following aspects (considering the completeness of data, we only searched the publications from 2009 to 2019): (1) the basic characteristics of publications are presented to describe development status, including the type of publications, annual number, citation number, and the productive contributors; (2) the top 15 most cited papers are listed. The influential countries/regions, institutions, and authors in the journal are provided, based on the total number of publications (TP), the total number of citations (TC), the number of citation-year distribution (C), the number of average citation (AC), $\mathrm{H}$-index, the number of publications that satisfy certain citations (i.e., $\geq 100, \geq 50)[22,23]$, etc. Besides, we also analyze the important cooperation relationship; (3) the co-citation analyses at the level of reference/source/authors, the burst detections of cited authors and cited journals, and the co-occurrence analyses and timeline view analysis of keywords are given, which is conducive to clear the development directions and the changes of research focus; (4) the future challenges of Symmetry are also discussed, combining with the above results.

The rest of this paper is organized as follows: Section 2 illustrates the data source and analyzes the basic characteristics, i.e., publications, citation numbers, and citation structure. The influential 
contributors in terms of papers, countries/regions, institutions, and authors are presented in Section 3. The co-citation and burst detections analyses are given in Section 4 . Section 5 focuses on the co-occurrence and timeline view analyses of keywords. Section 6 discusses the characteristics of this journal and presents future suggestions according to the whole analyses. Some conclusions are provided to end this paper in Section 7.

\section{Data Source and Basic Characteristics}

This paper mainly uses the bibliometric method to study the publications in Symmetry from 2009 to 2019. The literature data are from the Web of Science (WoS) Core Collection database on June 24, 2020, using Symmetry-Basel (we replace Symmetry-Basel with Symmetry below). Then, through the search for the journal's name, we found 3125 papers.

Base on the analytic results given by WoS, we obtain Figure 1 and find that the paper types published on Symmetry are classified into five kinds. The number of articles is 2941 and far more than other types of publications. This is followed by 161 reviews, 21 editorial material, 2 corrections, and 1 biographic item. This phenomenon shows that Symmetry focuses on academic articles. Then, the total number of publications (TP), the total number of citations distribution (TC), and the number of citation-year distribution (C) in the journal from 2009 to 2019 are illustrated in Figure 2. In this paper, we also use AC to denote the average number of citations per publication.

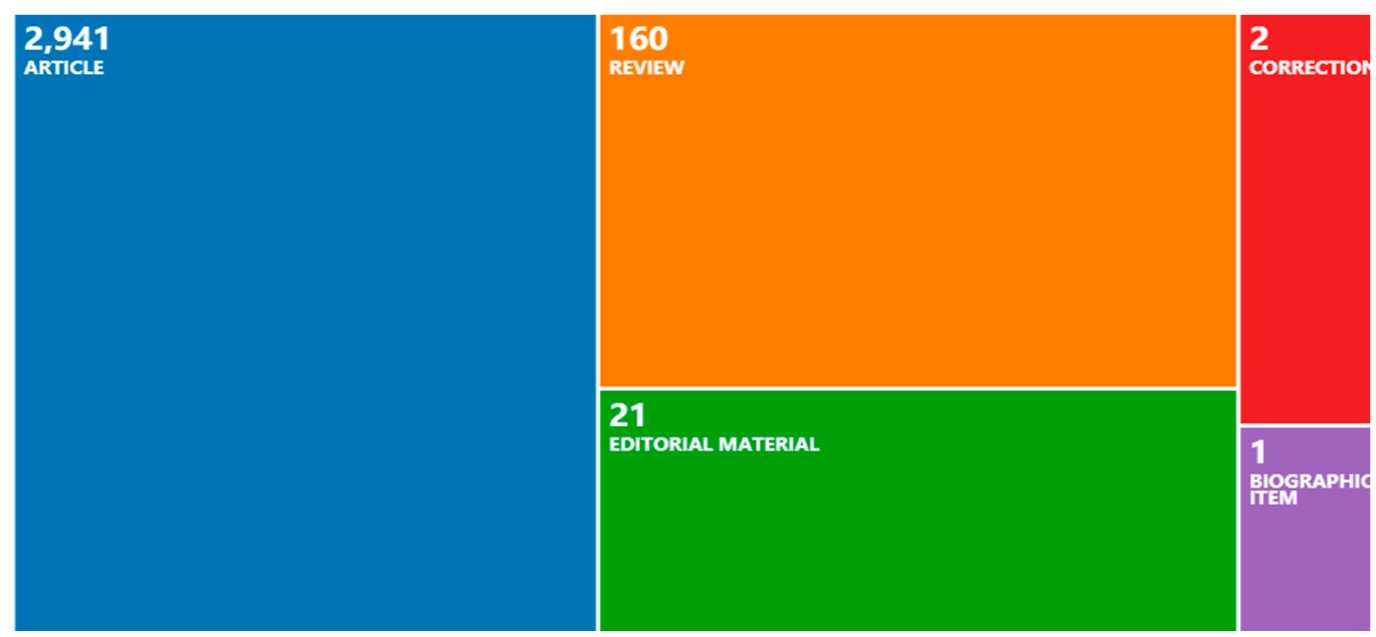

Figure 1. Types of the Symmetry publications.

From Figure 2a, the annual number of publications per year shows an increasing trend. To be specific, the annual publications were less than 100 before 2015. Then, it has been increasing rapidly, and the annual publications have been greater than 1000 in 2019, which shows that more and more scholars have paid attention to the journal.

Furthermore, Figure 2a describes the citation numbers of papers published in each year. The publications receive the most citations (3324) in 2018, followed by 2234 citations in 2019, and 1930 citations in 2017. The trend of citations had three peaks, i.e., in 2010 (1388), 2015 (918), and 2018 (3324), respectively. Figure $2 b$ illustrates the citation numbers of each year from 2009 to 2019 . We can see that the citation-year distributions increased year by year. In 2009, the number of citations was only 3; since 2011, the annual number of citations was more than 100. By 2018, the number of citations increased to 1840 , which denotes that Symmetry was paid close attention. The low citation-year, i.e., 2013, does not mean that no excellent studies appeared; the number of citations is dynamic and time is required for publications to be widely recognized and cited [24]. Table 2 is provided to explore more detailed information about Symmetry. Among the several indicators, $\mathrm{H}$-index considers both the number of publications and citations; the index without self-citations is an important indicator. A high $\mathrm{H}$-index 
implies a greater achievement [25]. Furthermore, different intervals reflect the number of citations; for example, $\geq 50$ denotes the number of publications that cited times great than or equal to 50 . From Table 2, the paper published in 2018 has the greatest TC (3324) and H-index (24), 2010 has the greatest AC (18). It is obvious that as time goes by, the influence of Symmetry has increased. Based on the data collection from WoS, only in 2010 and 2015 were there two papers that satisfy the standard of " $\geq 100$ ", and three papers were high-cited papers.

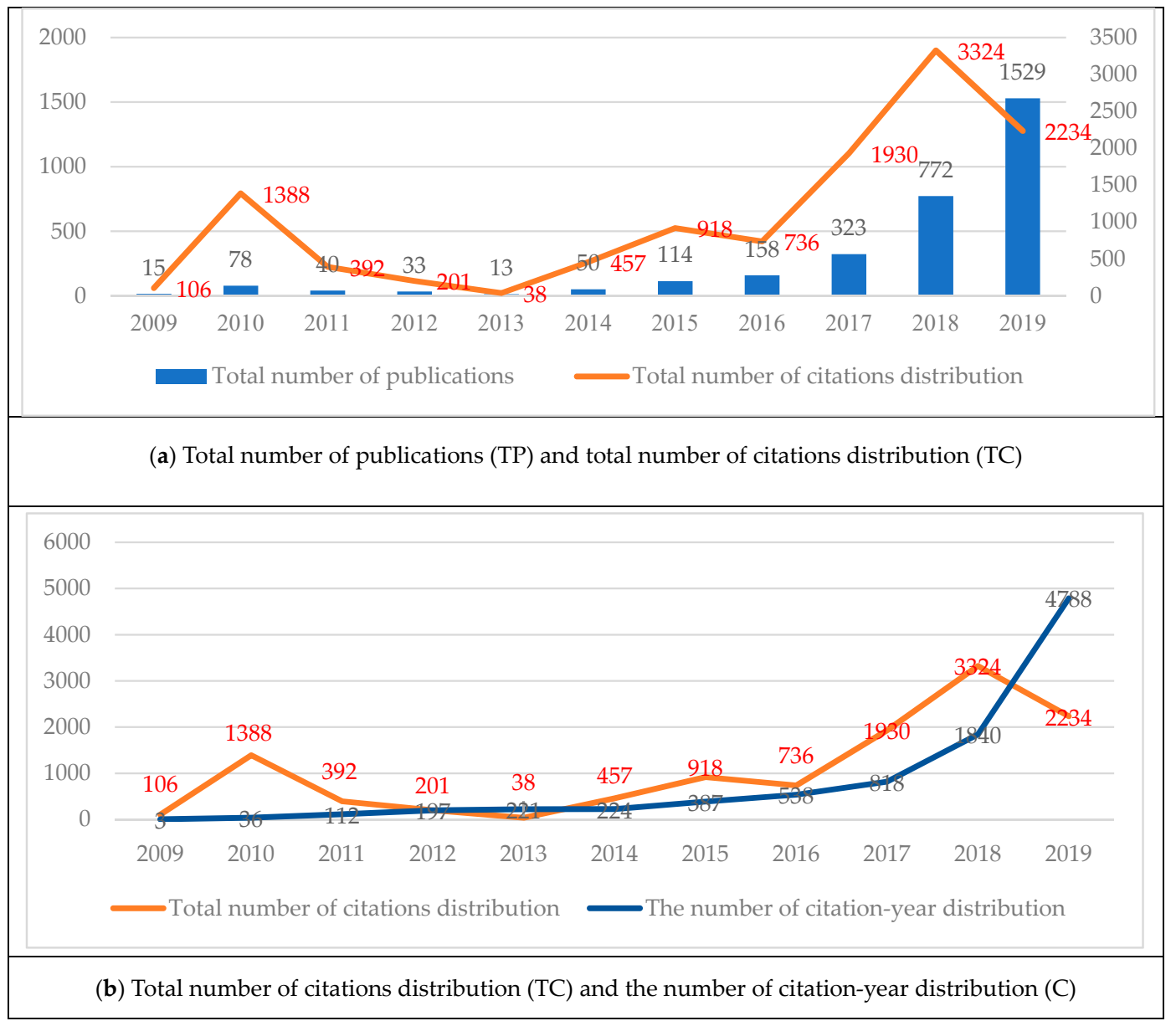

Figure 2. The number of publications and citations distribution.

Table 2. Symmetry publication characteristics from 2009 to 2019.

\begin{tabular}{cccccccccc}
\hline Year & TP & TC & AC & H-Index & $\geq \mathbf{1 0 0}$ & $\mathbf{2 5 0}$ & $\mathbf{2 0}$ & $\geq \mathbf{1 0}$ & $\geq \mathbf{5}$ \\
\hline 2009 & 15 & 106 & 7 & 6 & 0 & 0 & 2 & 4 & 6 \\
2010 & 78 & 1388 & $\mathbf{1 8}$ & 18 & 2 & 8 & 16 & 35 & 48 \\
2011 & 40 & 392 & 10 & 12 & 0 & 1 & 4 & 14 & 20 \\
2012 & 33 & 201 & 6 & 7 & 0 & 1 & 0 & 4 & 9 \\
2013 & 13 & 38 & 3 & 4 & 0 & 0 & 0 & 0 & 2 \\
2014 & 50 & 457 & 9 & 9 & 0 & 3 & 5 & 9 & 24 \\
2015 & 114 & 918 & 8 & 13 & 2 & 0 & 8 & 20 & 41 \\
2016 & 158 & 736 & 5 & 14 & 0 & 0 & 7 & 20 & 50 \\
2017 & 323 & 1930 & 6 & 20 & 0 & 1 & 21 & 57 & 128 \\
2018 & 772 & 3324 & 4 & $\mathbf{2 4}$ & 0 & 3 & 31 & 74 & 210 \\
2019 & $\mathbf{1 5 2 9}$ & 2234 & 1 & 15 & 0 & 3 & 10 & 37 & 109 \\
Total & 3125 & 11,724 & - & - & 4 & 20 & 104 & 274 & 647 \\
\hline
\end{tabular}

${ }^{1}$ TP: total number of publications; TC: the total number of citations distribution; AC: the average number of citations per publication, the same below. 
Next, this paper analyzes the productive objects, including countries/regions, institutions, and authors. The countries/regions with greater than 100 publications are presented in Figure 3 and then the top 10 productive institutions and authors are presented in Table 3. From Figure 3, we can see that the scholars in China have published 1226 papers and rank in the first place. Following, the scholars in the USA and South Korea both published more than 340 papers each, and rank in the second and the third places, respectively. The fourth to eleventh productive countries/regions are Spain (217), Pakistan (207), Saudi Arabia (177), Italy (118), Malaysia (114), Poland (109), Japan (107), and India (106).

In terms of institutions, China Medical University Taiwan published 66 papers and ranks first, followed by the National University of Defense Technology China (59), Beijing Jiaotong University (54), King Abdulaziz University (52), and the University of New Mexico (51), respectively. In the top 10 institutions, 6 of them are from China.

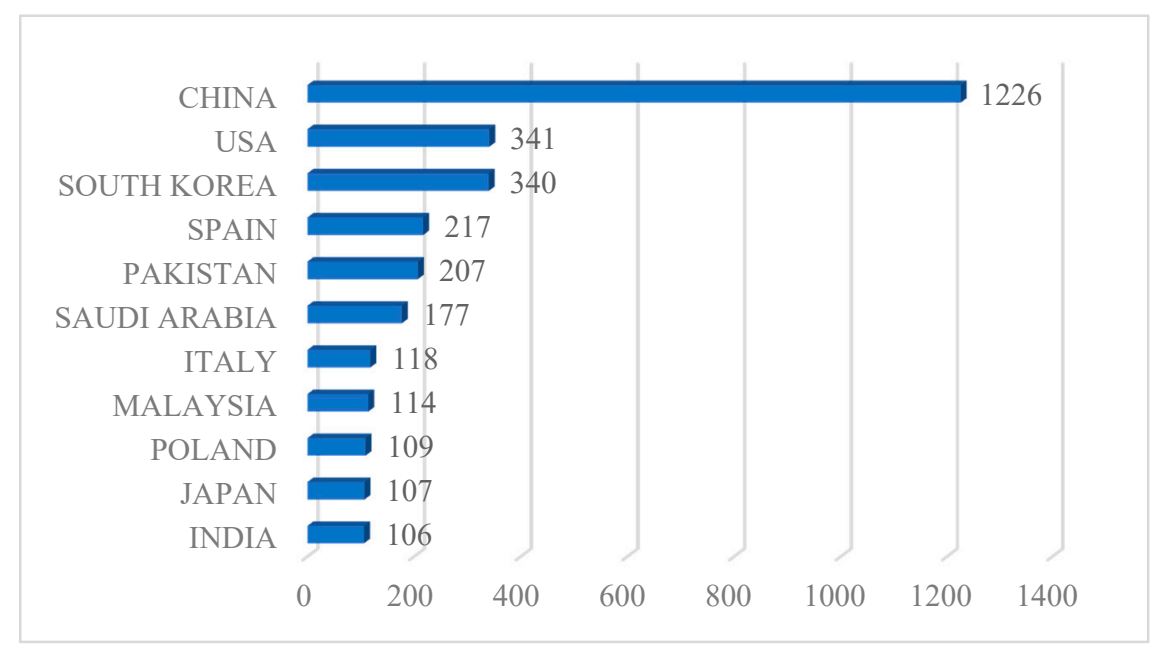

Figure 3. The 11 countries/regions with greater than 100 publications.

On the author's side, Smarandache F., from the USA, and Zhang X. H., from China, rank first and second, with 51 and 31 publications, respectively. Among the top 10 most productive authors, 4 of them are from China, 4 come from South Korea, 1 comes from the USA, and the other is Vietnamese. From the above three aspects, Symmetry has aroused special attention for scholars from China, the USA, and Korea.

Table 3. Top 10 productive Institutions/Authors in Symmetry.

\begin{tabular}{cccc}
\hline Institution & TP & Author & TP \\
\hline China Medical University Taiwan & 66 & Smarandache F. & 51 \\
National University of Defense Technology China & 59 & Zhang X.H. & 31 \\
Beijing Jiaotong University & 54 & Wang J. & 25 \\
King Abdulaziz University & 52 & Kim J. & 24 \\
University of New Mexico & 51 & Khan I. & 22 \\
Harbin Engineering University & 47 & Chang C.C. & 19 \\
Comsats University Islamabad Cui & 44 & Lee S. & 19 \\
Ton Duc Thang University & 41 & Kim D.S. & 18 \\
China Medical University Hospital Taiwan & 40 & Kim T. & 18 \\
Central South University & 39 & Park J.H. & 17 \\
\hline
\end{tabular}

Furthermore, the subject areas of Symmetry relate to physics, chemistry, biology, computer science, theory and methods, etc., which is multidisciplinary. Since it published papers, some publications impact the corresponding field. Table 4 lists the details of the top 15 most influential papers, including author, type, year, citation, etc. 
Table 4. The top 15 most cited papers in Symmetry from 2009 to 2019.

\begin{tabular}{|c|c|c|c|c|c|c|}
\hline & Title & Author(s) & Type & Year & Citation & Is it a High-Cited Paper \\
\hline 1 & Fluctuating asymmetry: methods, theory, and applications & Graham et al. & Review & 2010 & 183 & $\sqrt{ }$ \\
\hline 2 & Inflationary cosmology in modified gravity theories & Bamba and Odintsov & Review & 2015 & 175 & $\sqrt{ }$ \\
\hline 3 & $\begin{array}{l}\text { Analyzing fluctuating asymmetry with geometric morphometrics: } \\
\text { concepts, methods, and applications }\end{array}$ & $\begin{array}{l}\text { Klingenberg and } \\
\text { Christian }\end{array}$ & Review & 2015 & 125 & $\sqrt{ }$ \\
\hline 4 & Doubly-special relativity: facts, myths and some key open issues & Giovanni & Article & 2010 & 114 & \\
\hline 5 & One-sign order parameter in iron based superconductor & Borisenko et al. & Article & 2012 & 90 & \\
\hline 6 & Behind the looking-glass: a review on human symmetry perception & Trender & Review & 2010 & 90 & \\
\hline 7 & Organocatalytic enantioselective henry reactions & Yolanda et al. & Review & 2011 & 89 & \\
\hline 8 & $\begin{array}{c}\text { A critical assessment of the performance of magnetic and electronic } \\
\text { indices of aromaticity }\end{array}$ & Sola et al. & Review & 2010 & 87 & \\
\hline 9 & $\begin{array}{l}\text { On the harmonic oscillator model of electron delocalization (homed) } \\
\text { index and its application to heteroatomic pi-electron systems }\end{array}$ & Raczynska et al. & Article & 2010 & 84 & $\sqrt{ }$ \\
\hline 10 & $\begin{array}{l}\text { Models for green supplier selection with some 2-tuple linguistic } \\
\text { neutrosophic number Bonferroni mean operators }\end{array}$ & Wang et al. & Article & 2018 & 81 & \\
\hline 11 & $\begin{array}{l}\text { Spontaneous symmetry breaking and nambu-goldstone bosons in } \\
\text { quantum many-body systems }\end{array}$ & Brauner & Review & 2010 & 78 & \\
\hline 12 & Chiral liquid crystals: structures, phases, effects & Dierking & Review & 2014 & 70 & \\
\hline 13 & Synthesis and reactions of dibenzo [a,e] pentalenes & Saito & Review & 2010 & 65 & \\
\hline 14 & $\begin{array}{l}\text { Methods for multiple attribute group decision making based on } \\
\text { intuitionistic fuzzy dombi hamy mean operators }\end{array}$ & Li et al. & Article & 2018 & 64 & $\sqrt{ }$ \\
\hline 15 & Chlorophylls, dymmetry, chirality, and photosynthesis & Senge et al. & Review & 2014 & 61 & \\
\hline
\end{tabular}


From Table 4, 5 publications are articles and 10 publications are reviews. The top three cited publications are all reviews [26-28] and high-cited papers. Furthermore, two of them are studying fluctuating asymmetry, which has been widely investigated from basic theories, methods, and applications. Besides, the top 15 most cited papers were mainly published in 2010 (7), 2014 (2), 2015 (2), and 2018 (2). Furthermore, 10 of them have more than one author. Thus, the cooperation of authors also plays a key role in academic research.

\section{Influential Contributor Analyses}

According to Table 4, the frequency of the most cited paper is 183; it reviewed old and new methods of measuring fluctuation asymmetry and then reviewed the theory, developmental origins, and the applications of fluctuation asymmetry [26].

The paper "Inflationary cosmology in modified gravity theories" was cited 175 times; it reviewed inflationary cosmology in modified gravity [27]. The paper "Analyzing fluctuating asymmetry with geometric morphometrics: concepts, methods, and applications" ranks third place and was cited 125 times. The theme of this paper is the same as the most cited paper, i.e., fluctuating asymmetry. This paper summarized the concepts and morphometric methods for studying fluctuating asymmetry of shape and size.

In the top 15 most cited papers, we can find that there are only 2 papers published in recent years (in 2018); thus, the papers published in recent years still need time to gain attention. These data illustrate that the top 15 most cited papers all promote the development and advance of the journal and the related research fields.

Figure 4 depicts the cooperation network among countries/regions, where the nodes represent the countries/regions, and the sizes denote the citations; that is, the larger the size of the node, the greater the number of citations. The lines between two countries/regions denote that they cooperate. The density of the links of a country indicates the cooperation degree. The denser of the lines, the more collaboration for one country with other countries. From Figure 4, we can see that China, the USA, Pakistan, and the UK have more lines. Therefore, they have more cooperation with other countries.

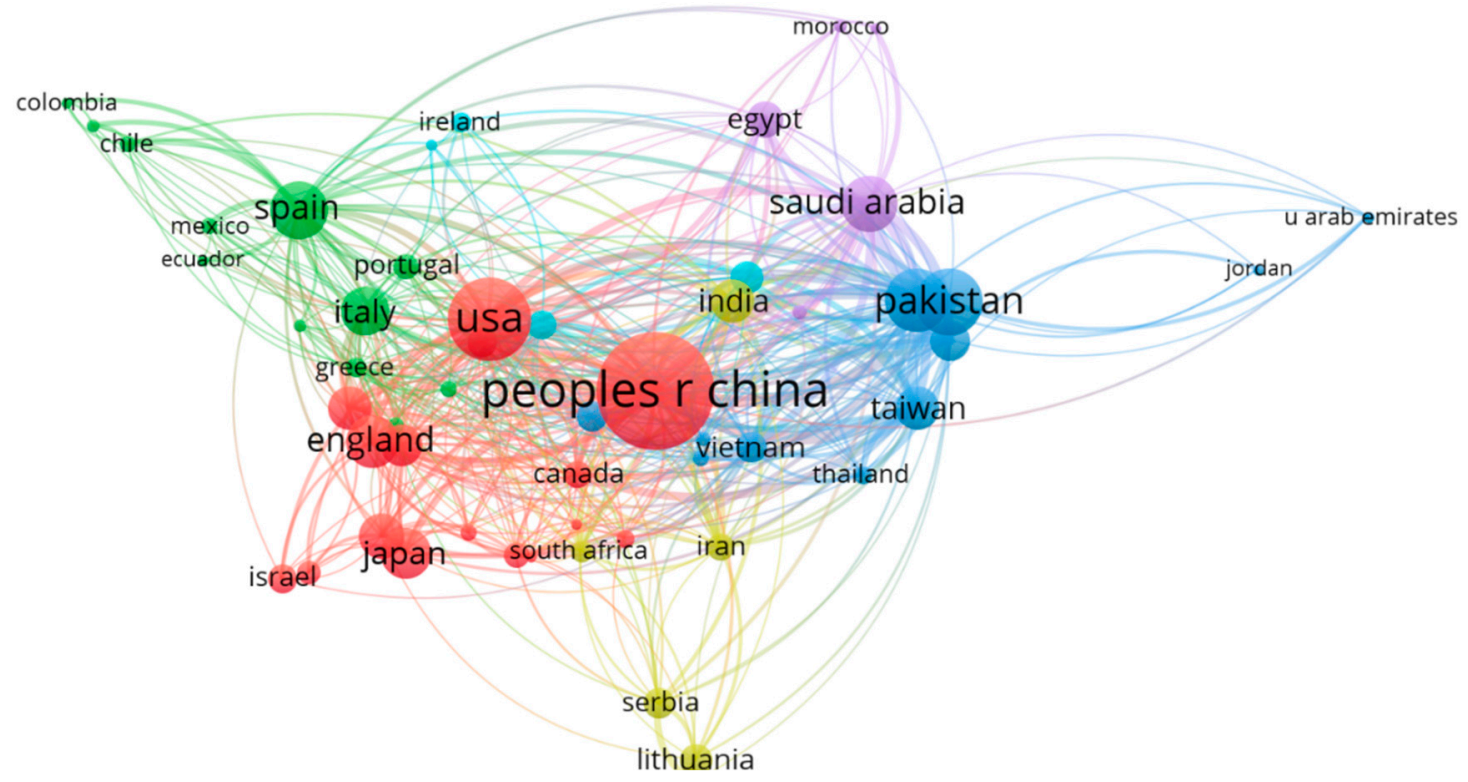

Figure 4. The co-authorship network of countries/regions.

Table 5 gives the top 10 most influential countries/regions and their corresponding data. China has the most citations (4002) and the highest H-index (24), which is consistent with Figure 4. For $\geq 100$, each of the USA, Spain, the UK, Japan, and Italy has one paper. Furthermore, it can be seen that 5 
papers from China have more than 50 citations, 36 papers have more than 20 citations, and 86 papers have more than 10 citations. There are 91 papers from the USA with more than 10 citations, which are far more than other countries. Thus, China and the USA are two biggest contributors to this journal. It is noted that, although the UK only has 96 publications on Symmetry, it has the highest AC with 7.28, which means that these papers play an important role in the related research fields. China and Saudi Arabia have 10 high-cited papers each. We also find that the top 10 most influential countries/regions are mainly from Asia and Europe.

Table 5. The top 10 most influential countries/regions.

\begin{tabular}{ccccccccccccc}
\hline & Countries & Continent & TP & TC & AC & H-Index & $\geq \mathbf{1 0 0}$ & $\geq \mathbf{5 0}$ & $\geq \mathbf{2 0}$ & $\geq \mathbf{1 0}$ & HC $^{\mathbf{1}}$ & HP \\
\hline 1 & China & Asia & $\mathbf{1 2 2 6}$ & $\mathbf{4 0 0 2}$ & 3.26 & $\mathbf{2 4}$ & 0 & 5 & 36 & 86 & 10 & 0 \\
2 & USA & North American & 341 & 1718 & 5.04 & 19 & 1 & 3 & 16 & 91 & 3 & 0 \\
3 & Pakistan & Asia & 207 & 1179 & 5.70 & 17 & 0 & 2 & 15 & 74 & 7 & 2 \\
4 & South Korea & Asia & 340 & 1011 & 2.97 & 15 & 0 & 0 & 9 & 61 & 1 & 0 \\
5 & Spain & Europe & 217 & 851 & 3.92 & 11 & 1 & 3 & 5 & 18 & 1 & 0 \\
6 & Saudi Arabia & Asia & 177 & 781 & 4.41 & 13 & 0 & 2 & 11 & 25 & 10 & 2 \\
7 & UK & Europe & 96 & 699 & $\mathbf{7 . 2 8}$ & 12 & 1 & 4 & 7 & 15 & 1 & 0 \\
8 & Japan & Asia & 107 & 669 & 6.25 & 12 & 1 & 3 & 5 & 17 & 1 & 0 \\
9 & Italy & Europe & 118 & 607 & 5.14 & 13 & 1 & 1 & 7 & 16 & 0 & 0 \\
10 & Poland & Europe & 109 & 505 & 4.63 & 11 & 0 & 2 & 6 & 14 & 1 & 0
\end{tabular}

${ }^{1} \mathrm{HC}$ : the number of the high-cited papers; HP: the number of the hot papers, the same below.

Furthermore, the top 10 most cited institutions are presented in Table 6. The University of New Mexico is the most cited institution, with 491 citations and $11 \mathrm{H}$-index, while its AC is only 9.63. Sichuan Normal University has 362 citations and ranks in second place. The University of Manchester has the greatest AC (43.30), even though it only has 5 papers, which explains the importance of these papers and the related research topics. Its most cited paper, Analyzing Fluctuating Asymmetry with Geometric Morphometrics: Concepts, Methods, and Applications, is the third most cited paper of Symmetry.

Table 6. The top 10 most influential institutions.

\begin{tabular}{cccccccccccc}
\hline & Institutions & TP & TC & AC & H-Index & $\mathbf{2 1 0 0}$ & $\mathbf{2 5 0}$ & $\geq \mathbf{2 0}$ & $\geq \mathbf{1 0}$ & HC & HP \\
\hline 1 & Univ New Mexico & 51 & $\mathbf{4 9 1}$ & 9.63 & $\mathbf{1 1}$ & 0 & 1 & 8 & 16 & 1 & 0 \\
2 & Sichuan Normal Univ & 9 & 362 & 40.22 & 7 & 0 & 3 & 7 & 7 & $\mathbf{4}$ & 0 \\
3 & Shaoxing Univ & 18 & 261 & 14.50 & 8 & 0 & 1 & 5 & 7 & 0 & 0 \\
4 & Shaanxi Univ Sci \& Technol & 30 & 246 & 8.20 & 8 & 0 & 0 & 3 & 8 & 2 & 0 \\
5 & Shanghai Maritime Univ & 27 & 241 & 8.93 & 8 & 0 & 0 & 4 & 8 & 1 & 0 \\
6 & China Med Univ & $\mathbf{6 7}$ & 249 & 3.72 & 9 & 0 & 0 & 2 & 7 & 1 & 0 \\
7 & Univ Manchester & 5 & 217 & $\mathbf{4 3 . 4 0}$ & 4 & 1 & 2 & 2 & 4 & 1 & 0 \\
8 & Berry Coll & 5 & 210 & 42.00 & 3 & 1 & 1 & 1 & 2 & 1 & 0 \\
9 & Vilnius Gediminas Tech Univ & 17 & 207 & 12.18 & 8 & 0 & 0 & 1 & 7 & 1 & 0 \\
10 & Tomsk State Pedag Univ & 10 & 206 & 20.60 & 3 & 1 & 1 & 1 & 2 & 1 & 0 \\
\hline
\end{tabular}

Next, the most cited authors are analyzed and the top 10 most influential authors are presented in Table 7. Smarandache F. has the greatest TC and H-index, ranking in the first place. Besides, even though each of Hel-Or Hagit, Nevo Eviatar, and Raz Shmuel only published two papers in Symmetry, their AC is the highest (95.50). Furthermore, they relate to the same paper, i.e., Fluctuating Asymmetry: Methods, Theory, and Applications, the most cited paper in Table 4. Graham, John H. ranks in second place of AC and is also the author of the same paper. This phenomenon can be explained by the cooperative relationship among authors. Then, we analyze the cooperation relationship and depict the corresponding science mapping as shown in Figure 5. 
Table 7. The top 10 most influential authors.

\begin{tabular}{cccccccccccc}
\hline & Authors & TP & TC & AC & H-Index & $\geq \mathbf{1 0 0}$ & $\mathbf{2 5 0}$ & $\mathbf{2} \mathbf{2 0}$ & $\mathbf{\geq} \mathbf{1 0}$ & HC & HP \\
\hline 1 & Smarandache F. & 51 & $\mathbf{4 8 9}$ & 9.59 & 11 & 0 & 1 & 8 & 16 & 1 & 0 \\
2 & Wei G.W. & 8 & 362 & 45.25 & 7 & 0 & 3 & 7 & 7 & 4 & 0 \\
3 & Wang J. & 11 & 266 & 24.18 & 5 & 0 & 2 & 5 & 5 & 3 & 0 \\
4 & Ye J. & 17 & 259 & 15.24 & 8 & 0 & 1 & 5 & 7 & 0 & 0 \\
5 & Zhang X.H. & 30 & 246 & 8.20 & 8 & 0 & 0 & 3 & 8 & 2 & 0 \\
6 & Graham J.H. & 3 & 205 & 68.33 & 3 & 1 & 1 & 1 & 2 & 1 & 0 \\
7 & Zavadskas E.K. & 12 & 194 & 16.17 & 8 & 0 & 0 & 3 & 7 & 1 & 0 \\
8 & Hel-Or H. & 2 & 191 & $\mathbf{9 5 . 5 0}$ & 2 & 1 & 1 & 1 & 1 & 1 & 0 \\
9 & Nevo E. & 2 & 191 & $\mathbf{9 5 . 5 0}$ & 2 & 1 & 1 & 1 & 1 & 1 & 0 \\
10 & Raz S. & 2 & 191 & $\mathbf{9 5 . 5 0}$ & 1 & 1 & 1 & 1 & 1 & 1 & 0 \\
\hline
\end{tabular}

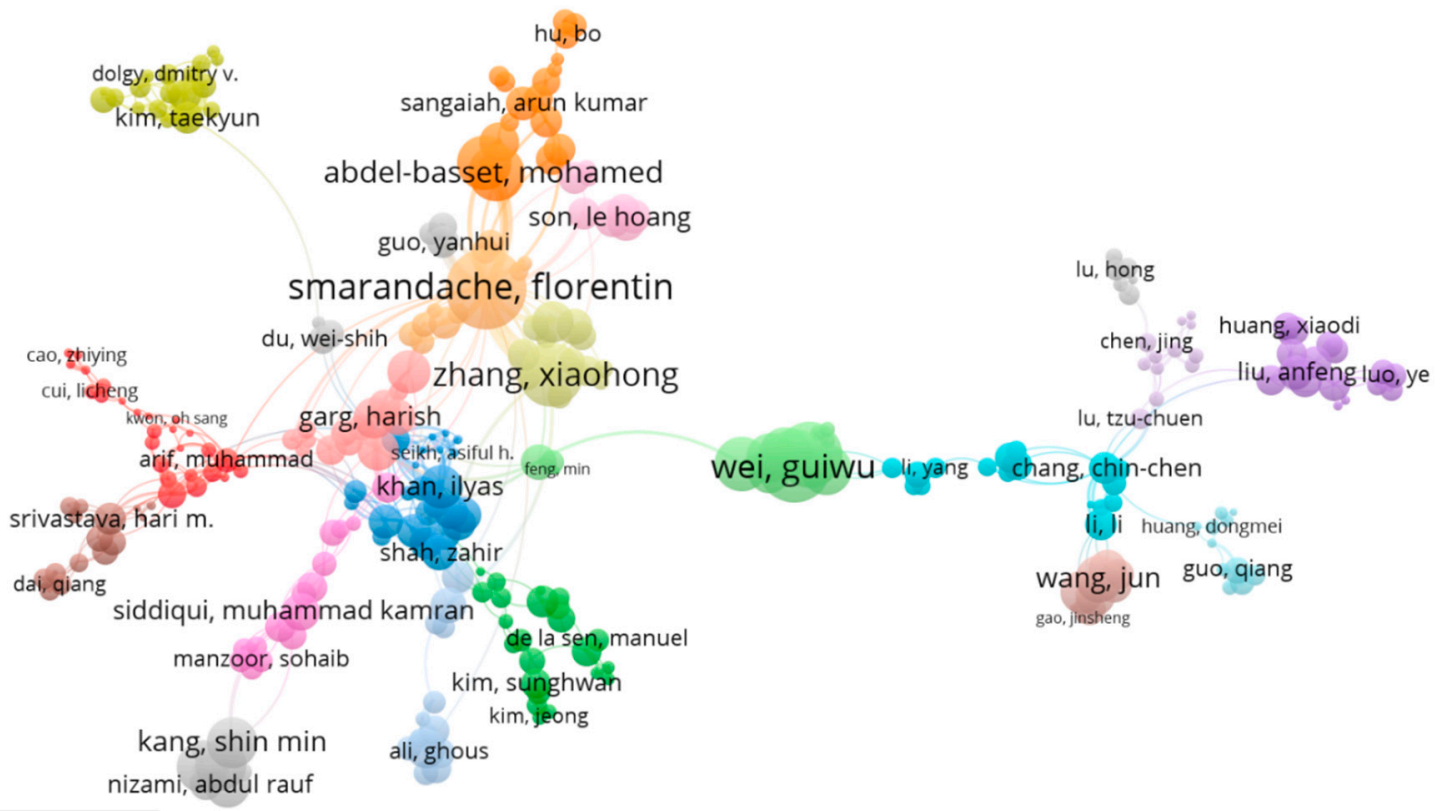

Figure 5. The closest cooperation relationship among authors in Symmetry.

The visualization of the cooperation network only presents 296 authors, which is the closest network by setting the minimum number of documents of an author as two. In Figure 5, the size of the node denotes the number of citations, for example, the node for Smarandache F., is the largest, followed by Wei G. W., which is consistent with Table 7. Besides, the links between the two authors mean that they cooperate. The links linked to Smarandache F. are the greatest, therefore having 43 links, $6.1 \%$ of the total links (704), and their total link strength is $99,8 \%$ of the whole link strength (1244). Then, Zhang X. H. has 16 links and a total link strength of 56, 4.5\% of 1244.

\section{The Co-Citation and the Burst Detection Analysis}

In this section, we make co-citation and the burst detection analysis by depicting visualizations combining with VOSviewer and CiteSpace. The co-citation analyses are conducted from the following aspects: reference co-citation, source co-citation, and author co-citation. Citation burst detection reflects the explosive data, that is, in a certain period, scholars' attention is attracted [29].

Figure 6 illustrates the closest reference co-citation network, where the threshold that denotes the minimum number of citations of a cited reference is 20 , and there are 31 references that satisfy the threshold. The closest network includes 25 references. In Figure 6, a node shows a reference, the size of the node denotes the citations number of the references. A link between two references means a co-citation relationship. The thicker the link is, the more citations the reference has. There are 5 
clusters marked with different colors. Furthermore, the paper Fuzzy sets, Information Control, 1965, 8, 2-3: 30-33 (cited 38,108 times) ranks in first place, with 203 citations in Symmetry. Similarly, the author and source co-citation networks are also be displayed. Then, Table 8 presents the top 10 most cited references/sources/authors by publications in Symmetry.

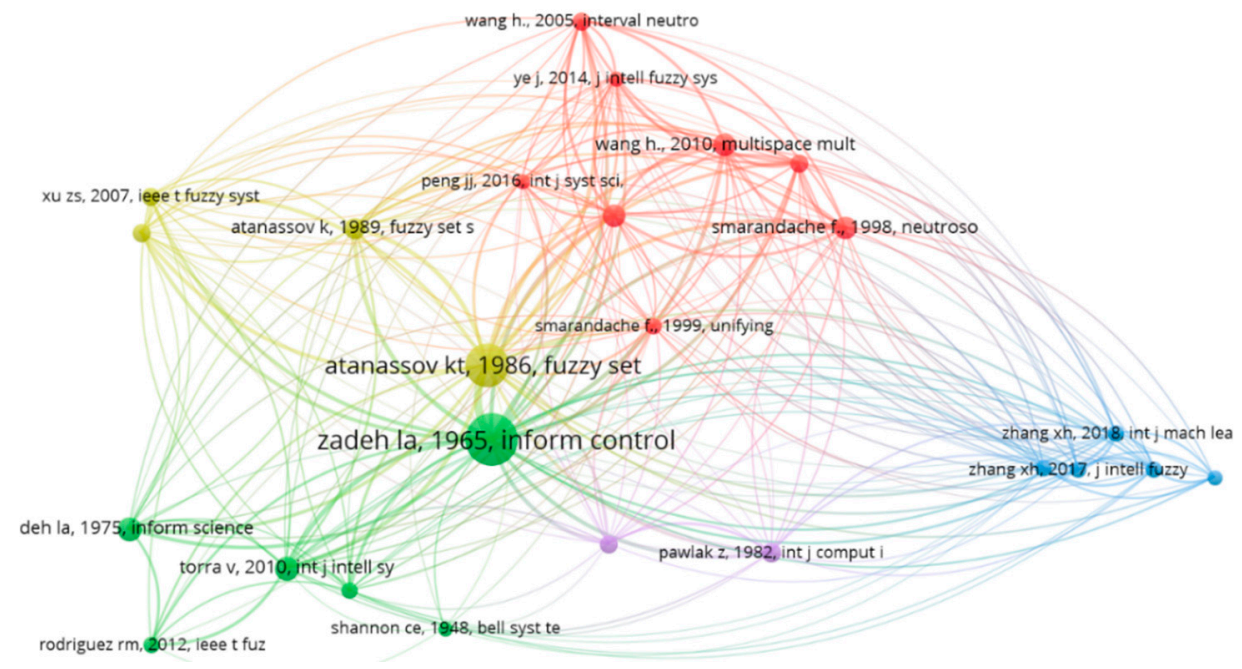

Figure 6. The closest co-citation network of references in Symmetry.

Table 8. The top 10 most cited references/sources/authors by publications in the journal.

\begin{tabular}{|c|c|c|c|c|c|c|}
\hline & Reference & TC & Source & TC & Author & TC \\
\hline 1 & Zadeh La, 1965, Inform. Control & 203 & Phys. Rev. D. & 2226 & Ye, J.H. & 336 \\
\hline 2 & Atanassov K, 1986, Fuzzy Set Syst. & 148 & Symmetry-Basel & 1858 & Smarandache, F & 331 \\
\hline 3 & Torra V, 2010, Int. J. Intell. Syst. & 49 & Phys. Rev. Lett. & 1468 & Zadeh, La & 307 \\
\hline 4 & Zadeh La, 1975, Inform. Sciences & 47 & Inform. Sciences & 951 & Liu, P.D. & 282 \\
\hline 5 & Smarandache F., 1998, Neutrosophy Neutroso & 45 & Lect. Notes Comput. Sc. & 867 & Wei, G.W. & 267 \\
\hline 6 & Wang H., 2010, Multispace Multistru & 43 & Phys. Lett. B & 862 & Xu, Z.S. & 241 \\
\hline 7 & Ye J, 2014, J. Intell. Fuzzy Syst. & 42 & Fuzzy Set. Syst. & 816 & Kim, T & 229 \\
\hline 8 & Atanassov K, 1989, Fuzzy Set. Syst. & 38 & Expert Syst. Appl. & 778 & Zhang, X.H. & 229 \\
\hline 9 & Pawlak Z, 1982, Int. J. Comput. Inf. Sci. & 35 & J. Intell. Fuzzy Syst. & 735 & Atanassov, K.T. & 184 \\
\hline 10 & Wang H., 2005, Interval Neutrosophi & 31 & Phys. Rev. A & 728 & Kostelecky, V.A. & 176 \\
\hline
\end{tabular}

Table 8 lists the information of the top 10 most cited references/sources/authors by publications in Symmetry. Six of references are published before 2010, and the first cited reference is from 1965 by Zadeh [30]. Only two references had a number of citations more than 100. Phys. Rev. D ranks the first cited source with 2226 citations. In terms of cited authors, Ye, J. H. received the most citations, with 336, followed by Smarandache, F (331) and Zadeh, La (307).

Through detecting bursts, Table 9 lists the top 10 cited authors of publications in Symmetry with the strongest citation bursts. Zadeh La on the top of the list with the maximum burst strength of 17.965. All of them have a citation burst duration with three years and close to the present (from 2018 to 2019), which shows that their work may have formed a hot and leading topic. 
Table 9. Top 10 cited authors with the strongest citation bursts.

\begin{tabular}{ccccccc}
\hline & Cited Authors & Year & Strength & Begin & End & 2009-2019 \\
\hline 1 & Zadeh La & 2009 & 17.965 & 2018 & 2019 & \\
2 & Atanassov K.T. & 2009 & 12.435 & 2018 & 2019 & \\
3 & Smarandache F. & 2009 & 12.1931 & 2018 & 2019 & \\
4 & Zhang X.H. & 2009 & 11.7661 & 2018 & 2019 & \\
5 & Ye. J. & 2009 & 11.2671 & 2018 & 2019 & \\
6 & Xu Z.S. & 2009 & 10.3632 & 2018 & 2019 & \\
7 & Torra V. & 2009 & 9.7113 & 2018 & 2019 & \\
8 & Chen S.M. & 2009 & 9.7113 & 2018 & 2019 & \\
9 & Wang H. & 2009 & 9.5661 & 2018 & 2019 & \\
10 & Wang J.Q. & 2009 & 9.3017 & 2018 & 2019 & \\
\hline
\end{tabular}

Table 10 presents the top 15 cited journals with the strongest citation bursts from 2009 to 2019. The cited journals receive frequent citations by Symmetry in a certain period. The citation bursts of the cited journals of Inform. Control. had the longest strength (39.1302). Besides, 5 of the top 15 cited journals had the longest duration, with 8 years from 2009 to 2016, which means that the publications in Symmetry cited these journals earlier and explosively. Of these 15, 7 are the closest to 2019, such as Inform. Control., Knowl-Based Syst., and IEEE T. Fuzzy Syst., which illustrates that they still have an influence on Symmetry and can even influence the future research directions.

Table 10. Top 15 cited journals with the strongest citation bursts.

\begin{tabular}{|c|c|c|c|c|c|c|}
\hline & Cited journals & Year & Strength & Begin & End & 2009-2019 \\
\hline 2 & Knowl-Based Syst & 2009 & 37.1671 & 2017 & 2019 & 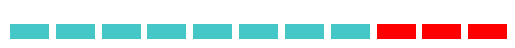 \\
\hline 4 & J. Math Phys. & 2009 & 30.0428 & 2009 & 2016 & Q \\
\hline 5 & Soft Comput. & 2009 & 30.0041 & 2017 & 2019 & שמ \\
\hline 8 & J. Phys. A-math Gen. & 2009 & 24.9067 & 2009 & 2016 & 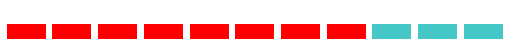 \\
\hline 9 & IEEE T. Pattern Anal. & 2009 & 23.3408 & 2014 & 2019 & 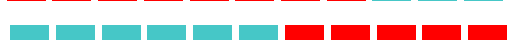 \\
\hline 10 & Rev. Mod. Phys. & 2009 & 20.8109 & 2009 & 2016 & 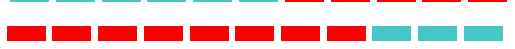 \\
\hline 11 & Science & 2009 & 20.0597 & 2010 & 2016 & رس \\
\hline 15 & Phys. Rev. B & 2009 & 17.2365 & 2009 & 2016 & 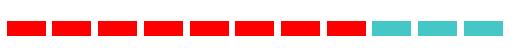 \\
\hline
\end{tabular}

\section{Co-Occurrence and Timeline Analyses of Keywords}

This section analyzes the co-occurrence of author-keywords and presents the timeline view. In the $1980 \mathrm{~s}$, the co-occurrence analysis was first provided and has been widely applied in bibliometrics analyses [31]. When more than or equal to two keywords appear in the same paper, this can be called keywords occurrence [32]. Through the co-occurrence analysis, we can identify the research hotspots of the journal.

There are 11,731 author-keywords of publications in the journal from 2009 to 2019, according toVOSviewer. Figure 7 presents the author-keywords co-occurrence network, where there are 164 author-keywords, by setting the threshold of minimum occurrences to five and giving the closest relationship. They are classified into 16 clusters marked in different colors. The node presents an author-keyword; its size denotes the citations. The bigger the node is, the more citations the keyword has. A link between two nodes means the co-occurrence of the two keywords. In Figure 7, symmetry has the greatest citations; therefore, it has the most links with other clusters. Then, we present the top 20 most frequent author-keywords and their frequencies in Table 11. 


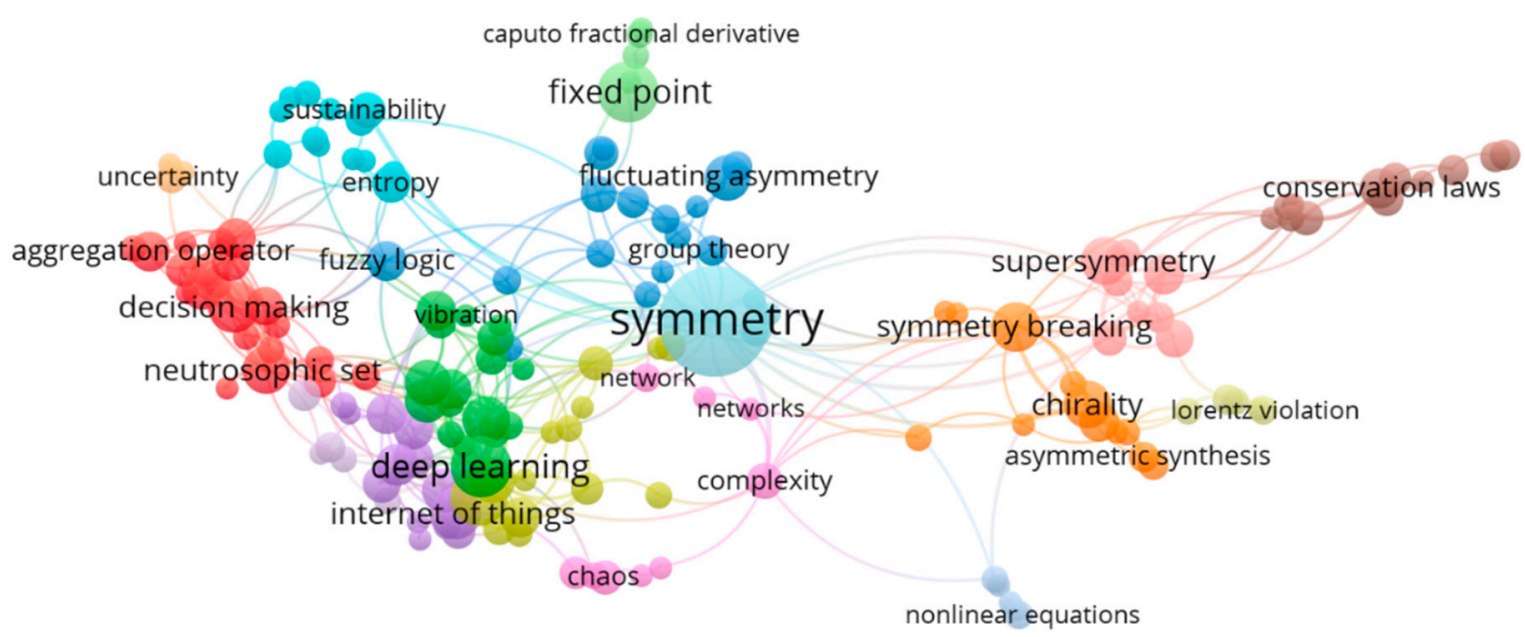

Figure 7. The co-occurrence network of author-keywords.

Table 11. The top 20 most frequent author-keywords in Symmetry.

\begin{tabular}{cccccc}
\hline Rank & Author-Keyword & Frequency & Rank & Author-Keyword & Frequency \\
\hline 1 & symmetry & 92 & 11 & chirality & 18 \\
2 & decision making & 37 & 12 & big data & 17 \\
3 & deep learning & 30 & 13 & convolutional neural network & 17 \\
4 & fixed point & 29 & 14 & fluctuating asymmetry & 17 \\
5 & machine learning & 27 & 15 & cloud computing & 16 \\
6 & internet of things & 22 & 16 & image processing & 16 \\
7 & symmetry breaking & 20 & 17 & clustering & 15 \\
8 & neural network & 19 & 18 & aggregation operator & 14 \\
9 & neutrosophic set & 19 & 19 & classification & 14 \\
10 & supersymmetry & 19 & 20 & data mining & 14 \\
\hline
\end{tabular}

The frequency of symmetry is 92 and ranks first. Following, decision making (37), deep learning (30), fixed point (29), and machine learning (27) rank in the second to fifth place, respectively, which explain the research topics of the journal. The frequencies of all the keywords in Table 11 are higher than 10 , and seven of them have frequencies greater than 20.

Table 12 explains the top 20 keywords with the strongest citation bursts. Most of them are close to present (2019), such as fuzzy set, decision making, aggregation operator, deep learning, etc., which denote that the research contents in the publications of Symmetry closely follow hot topics and leading issues. Comparing Table 11 with Table 12, we can find several of the same keywords, i.e., symmetry, decision making, symmetry breaking, neutrosophic set, and deep learning. This phenomenon explains that these are the research hotspots of the journal from 2009 to 2019; at the same time, the research fever of these may continue. Thus, the scholars interested in the journal can start from these research topics. 
Table 12. The top 20 keywords with the strongest citation bursts.

\begin{tabular}{|c|c|c|c|c|c|c|}
\hline & Keywords & Year & Strength & Begin & End & 2009-2019 \\
\hline 1 & fuzzy set & 2009 & 18.3082 & 2017 & 2019 & ש \\
\hline 2 & aggregation operator & 2009 & 11.0627 & 2018 & 2019 & D \\
\hline 3 & number & 2009 & 10.6203 & 2018 & 2019 & 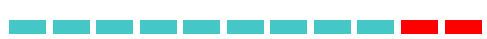 \\
\hline 4 & symmetry & 2009 & 9.8647 & 2009 & 2014 & D \\
\hline 5 & similarity measure & 2009 & 9.2729 & 2018 & 2019 & 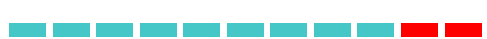 \\
\hline 6 & information & 2009 & 8.9273 & 2017 & 2019 & 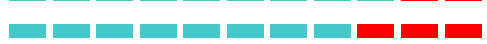 \\
\hline 7 & decision making & 2009 & 8.7959 & 2017 & 2019 & 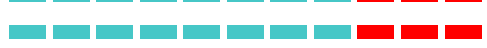 \\
\hline 8 & operator & 2009 & 8.3778 & 2018 & 2019 & 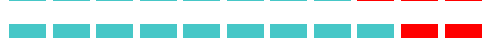 \\
\hline 9 & environment & 2009 & 6.5953 & 2018 & 2019 & 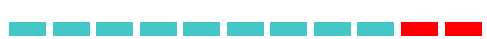 \\
\hline 10 & symmetry breaking & 2009 & 6.3503 & 2010 & 2010 & 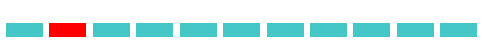 \\
\hline 11 & TOPSIS & 2009 & 5.7079 & 2018 & 2019 & 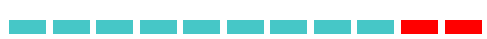 \\
\hline 12 & network & 2009 & 5.6572 & 2017 & 2019 & ع ص \\
\hline 13 & neutrosophic set & 2009 & 5.2651 & 2018 & 2019 & ש \\
\hline 14 & deep learning & 2009 & 5.2651 & 2018 & 2019 & ש \\
\hline 15 & management & 2009 & 5.2651 & 2018 & 2019 & 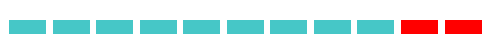 \\
\hline 16 & evolution & 2009 & 5.0578 & 2015 & 2016 & 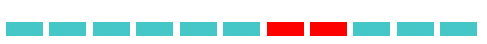 \\
\hline 17 & intuitionistic-fuzzy & 2009 & 5.0308 & 2017 & 2017 & 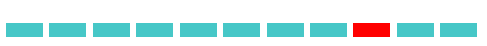 \\
\hline 18 & group-decision-making & 2009 & 5.0308 & 2017 & 2017 & 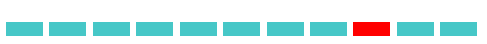 \\
\hline 19 & attribute-decision-making & 2009 & 5.0308 & 2017 & 2017 & 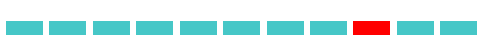 \\
\hline 20 & scheme & 2009 & 4.9364 & 2018 & 2019 & 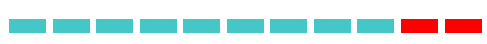 \\
\hline
\end{tabular}

Figure 8 shows the keyword clusters visualizations by CiteSpace and summarizes nine clusters for all keywords of publication in Symmetry, which are "exact solution", "decision making", "aromaticity", "aesthetic", "deep learning", "cyclic twin", "fixed point", "quantum theory", and "drosophila melanogaster" in order.

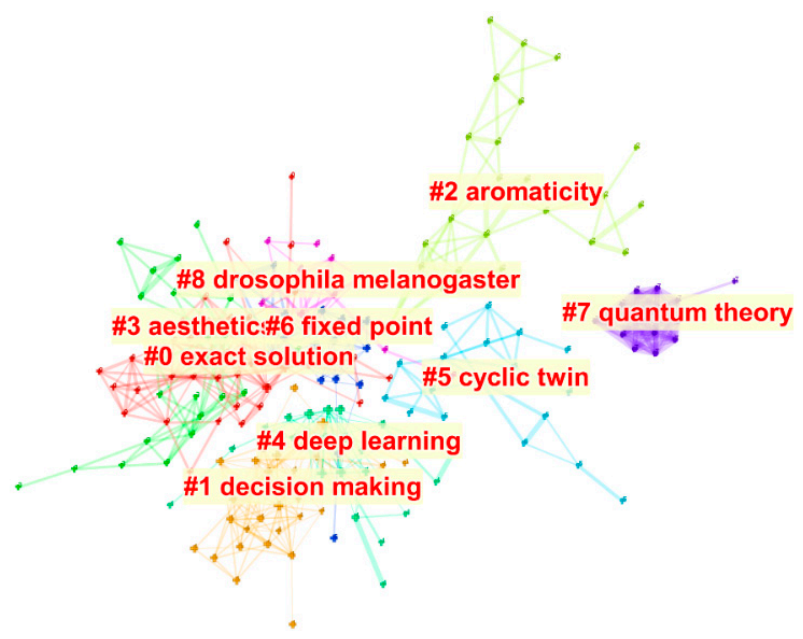

Figure 8. The keywords clusters visualizations.

Then, based on the timeline view of keywords, the development and the research trend of the hotspots from 2009 to 2019 are presented. In Figure 9, there are four stages from the time perspective. Specifically, it focused more on the "symmetry property", "simulation", "aromaticity", "model", and so on, between 2009 and 2010. The keywords of "tilling aperiodicity" and "symmetry group of knot" occurred most from 2010 to 2013. Next, from 2013 to 2016, a large number of research topics emerged, such as "exact solution", "framework", "three-dimensional space", "neural network", "equational simulation", "fluctuating asymmetry", etc. For the next phase, the publication preferred to occur keywords like "operator", "convolutional neural network", and "support vector machine". We can see that keywords continually change over time, and scholars expanded and deepened the research content on the journal. 


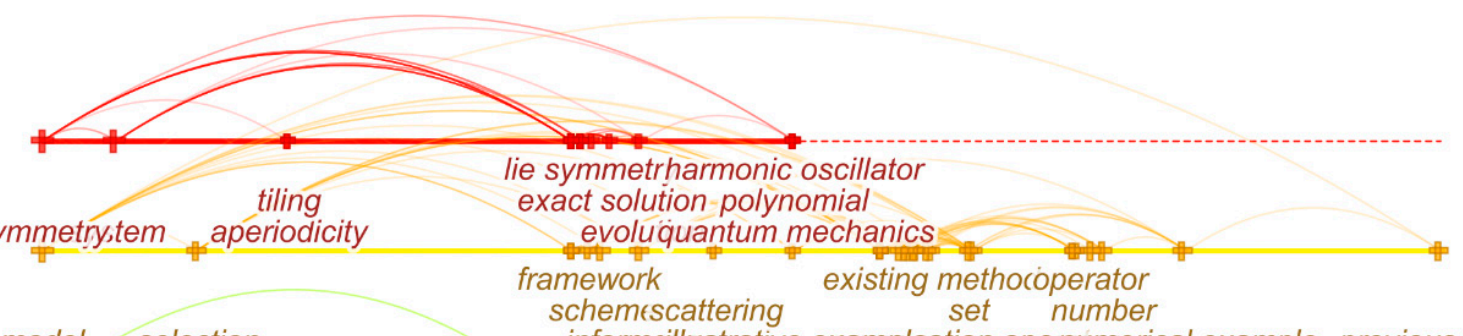

\section{\#0 exact solution}

\section{\#1 decision making}

existing methocoperator

model selection \# informeillustrative exampleation openumerical example previous study aromaticity by-two matrice

chirality lorentz-transformationutrino

simulation lorentz gamplification space

$\begin{array}{cc}\text { preferencesymmetry } & \text { three-dimensional space } \\ \text { attractivenessaph } & \text { four-dimensional space }\end{array}$

four-dimensional space'

Visual systemosmology

lower-bound optimizattime series deep learning

work algorithrneural network design performance support vector machir\#5 cyclic twin

topologymetry group of knot nucleation symmetry:propertyition =link groupitheory, group knot growth chain
chation

magnetic field growth

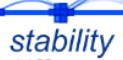

stability

equationerical simulation

\#6 fixed point

fermion

quantum theory

reprprobability theory

entanglement

simple model

symmetry breaking

developmental instability

developmental suifäce

fluctuating asymmechanism

\#2 aromaticity

\#3 aesthetics

\#4 deep learning

Figure 9. The timeline view of keywords for publications. 
Moreover, this paper also retrieves the papers published in 2020 and obtains 691 papers. Figure 10 shows the author-keywords co-occurrence network of these papers by setting the minimum number of occurrences of a keyword to two and displaying the closest network, which is related to 138 keywords. The side of the nodes denotes the frequency of co-occurrence. We can see that machine learning has the greatest frequency (24), followed by symmetry (20), deep learning (9), fixed point (9), asymmetry (8), dark matter (8), classification (7), dark energy (7), fuzzy logic (7), etc. The tenth to twentieth author-keywords are internet of things, particle swarm optimization, sustainability, conservation laws, convergence, hermite-hadamard inequality, stability analysis, ahp, artificial intelligence, bioconvection, and cloud computing.

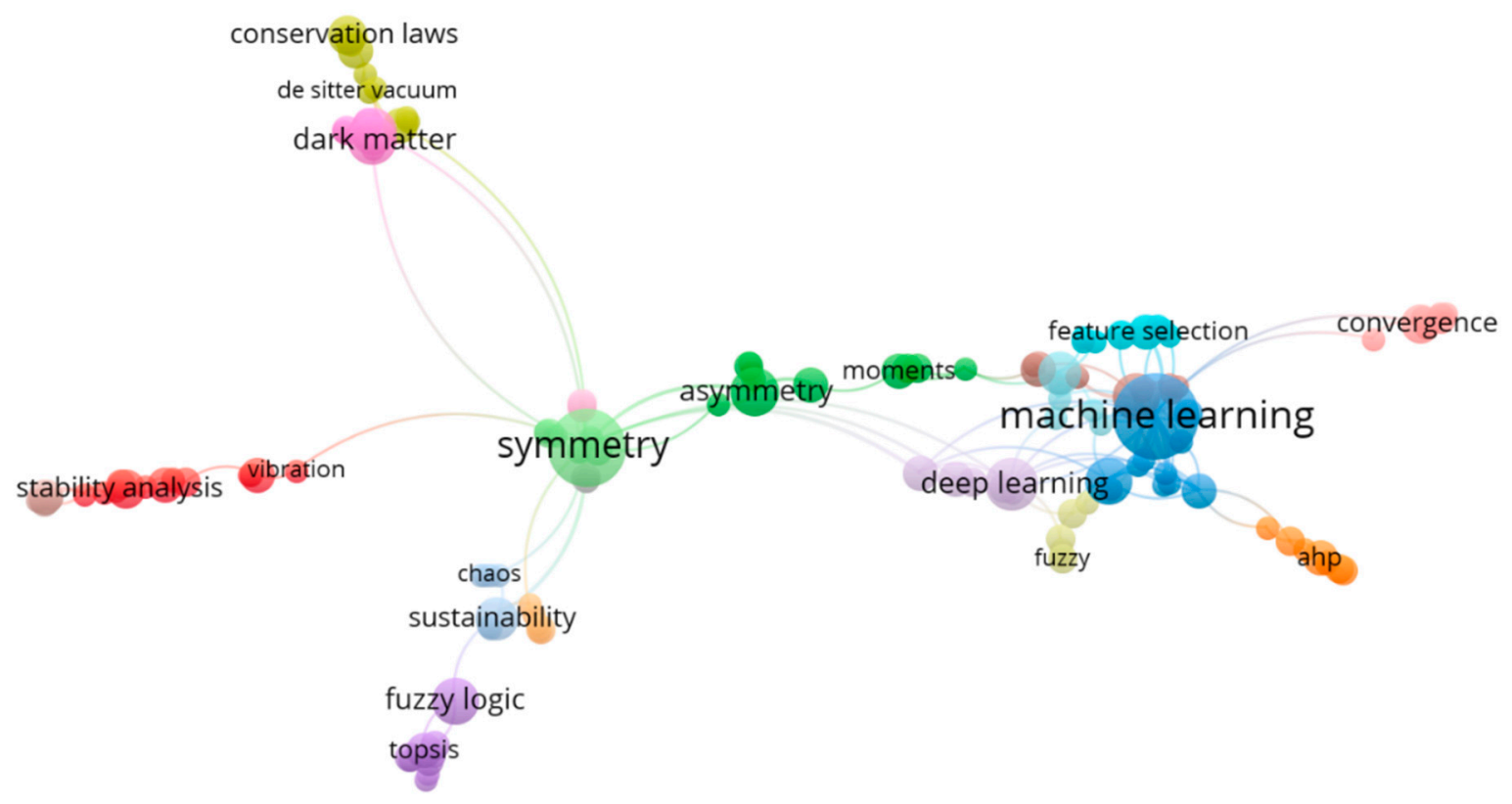

Figure 10. Author-keywords co-occurrence network of publications in 2020.

\section{Discussions}

This journal explores symmetry phenomena related to mathematical, physics, interdisciplinary fields, etc. After the bibliometric analysis, we further discussed the possible reasons and given future suggestions. According to analyses of Symmetry, the basic characteristics, citation structures, and productive objects are summarized as follows:

(1) The most frequent type of publication is the article, occupying $94.11 \%$ of the publications. There were more high-quality papers published in 2020, 2017, and 2018, in the view of TC and H-index. The trend of the publication-year distribution increased from 2013 to 2019. As of June, 2020, the publications received the most citations (3324) in 2018. The publications in 2019 were cited 2234 times; this year not only had the greatest number of papers, but also ranks second place in terms of citation frequency, the reason for which may be that an increasing amount of scholars are paying attention to the journal.

(2) Since most of the top 15 cited publications are cooperative, communication plays a key role in improving the level of publications. From the cooperation network, China receives the largest number of cooperation and is at the core place; at the same time, it is the country with the greatest number of publications.

(3) Publications cover 100 countries/regions, and the most influential countries/regions are mainly from Asia and Europe. In terms of TP, TC, and H-index, China led, which shows that publications in Symmetry from China have higher influence, followed by the USA. From the top 10 most cited references/sources/authors: (a) the publications cite reference universally; (b) the cited sources are 
mostly in the field of physics and fuzzy mathematics; (c) the researchers can pay close attention to the papers of the top cited authors and sources.

(4) Combined with the strong citation burst analyses, we can find that the top 10 lists between Tables 8 and 9 are different. This phenomenon explains that the author citation bursts at various times, and especially the emergence of some new authors, including Torra V. and Wang H. For the same authors, the ranks also exist discrepancy. The reason may be that the research topics of the journal are constantly enriched and there are diverse focuses, i.e., from physics to comprehensive discipline, including decision making, fuzzy mathematic, and deep learning.

(5) Considering the top 20 most frequent author-keywords and the top 20 keywords with the strongest citation bursts, in recent years, the main research contents of Symmetry focus on fuzzy set, aggregation operation, etc. The burst detection and the timeline view analyses of keywords show the knowledge structure and research trends in the journal. According to the results, the following topics can be considered in the future: (a) to process the complex and diverse raw data, and investigate new operators; (b) to study the symmetry phenomena in the artificial intelligence; (c) to excavate the symmetry nature in matching problems, aimed at solving more social management problems; (d) to predict the possible time change trends and their weights in dynamic issues; (e) to study the intelligent algorithms and promote their stability and reliability.

Due to the characteristics of publications, the most influential objects, and the co-occurrence analyses of author-keywords, regarding the publications from 2009 to 2019 in Symmetry, we find that, although the papers were first published in 2009, the numbers of publications have been increasing until the present. From 2015, the annual number of publications always exceeded 100. This suggests that the journal has constructed its influence on multidisciplinary theory and practice. Especially, authors from Asia and Europe pay more attention to this journal. In the future, it can expand its influence through cooperation. Then, the analyses results suggest that scholars should investigate advanced techniques (such as neural network, data mining, fuzzy decision-making, etc.) to keep pace with the times and solve the practical problems. Besides, with the uncertainty and diversification of the environment, enriching the research contents of the journal, at the same time, promoting the robustness of theory methods, etc. are also challenges for future scholars.

\section{Conclusions}

This paper presents a bibliometric analysis of Symmetry from 2009 to 2019 based on WoS. According to VOSviewer and CiteSpace, the analyses are conducted from the following aspects: basic characteristics, including the publications, citation number and citation structure; the influential objects; co-citation contributors and the burst detection analyses; the author-keywords co-occurrence analyses and timeline view analysis. The number of publications has almost increased every year since 2014 . The year 2019 was the year with the largest volume of publications and 2018 was the year with the most citations. China is the most productive and influential country. The top three productive institutions are China Medical University Taiwan (China), National University of Defense Technology China (China), and Beijing Jiaotong University (China), respectively. The prominent author is Smarandache F. According to the results, cooperation among contributors also plays a key role in the publications. In the view of author-keyword analyses, the scopes of Symmetry are constantly enriching and no longer limited to the symmetry phenomena in the fields of physics and chemistry. At present, these include decision making, fuzzy mathematics, deep learning, machine learning and classification, etc. We also discuss possible reasons for this and future development.

In summary, this paper is a relatively comprehensive view of Symmetry by bibliometric analysis, which helps scholars understand its current status, future trends of development, and research scope. In future, we will continue to collect its productions and pay more attention to its developments, aiming to make the conclusions richer.

Author Contributions: Conceptualization, Z.X.; data curation, J.A.; formal analysis, Z.T.; investigation, B.L.; methodology, Z.X.; project administration, Z.X.; supervision, E.K.Z; validation, E.K.Z.; writing一original draft, 
B.L.; writing-review and editing, J.A. and Z.T. All authors have read and agreed to the published version of the manuscript.

Funding: This work was funded by the National Natural Science Foundation of China under Grant 71771155.

Conflicts of Interest: The authors declare no conflict of interest.

\section{References}

1. Laengle, S.; Merigo, J.M.; Miranda, J.; Slowinski, R.; Bomze, I.; Borgonovo, E.; Dyson, R.G.; Oliveira, J.F.; Teunter, R. Forty years of the European Journal of Operational Research: A bibliometric overview. Eur. J. Oper. Res. 2017, 262, 803-816. [CrossRef]

2. Yu, D.J.; Xu, Z.S.; Saparauskas, J. The evolution of "Technological and Economic Development of Economy": A bibliometric analysis. Technol. Econ. Dev. Econ. 2019, 25, 369-385. [CrossRef]

3. Yu, D.J.; Xu, Z.S.; Pedrycz, W.; Wang, W.R. Information Sciences 1968-2016: A retrospective analysis with text mining and bibliometric. Inf. Sci. 2017, 418, 619-634. [CrossRef]

4. Yu, D.J.; Xu, Z.S.; Kao, Y.S.; Lin, C.T. The structure and citation landscape of IEEE Transactions on Fuzzy Systems (1994-2015). IEEE Trans. Fuzzy Syst. 2018, 26, 430-442. [CrossRef]

5. Zhou, W.; Xu, Z.S.; Zavadskas, E.K. A bibliometric overview of International Journal of Strategic Property Management between 2008 and 2019. Int. J. Strateg. Prop. Manag. 2019, 23, 366-377. [CrossRef]

6. Yu, D.J.; Xu, Z.S.; Antucheviciene, J. Bibliometric analysis of the Journal of Civil Engineering and Management between 2008 and 2018. J. Civ. Eng. Manag. 2019, 25, 402-410. [CrossRef]

7. Zhou, W.; Xu, Z.S.; Zavadskas, E.K.; Laurinavičius, A. The knowledge domain of the Baltic Journal of Road and Bridge Engineering between 2006 and 2019. Balt. J. Road Bridge E. 2020, 15, 1-30. [CrossRef]

8. Liu, W.S.; Liao, H.C. A bibliometric analysis of fuzzy decision research during 1970-2015. Int. J. Fuzzy Syst. 2017, 19, 1-14. [CrossRef]

9. Hache, E.; Palle, A. Renewable energy source integration into power networks, research trends and policy implications: A bibliometric and research actors survey analysis. Energy Policy 2019, 124, 23-35. [CrossRef]

10. Yu, D.J.; Xu, Z.S.; Wang, X.X. Bibliometric analysis of support vector machines research trend: A case study in China. Int. J. Mach. Learn Cybern. 2019, 11, 715-728.

11. Stopar, K.; Bartol, T. Digital competences, computer skills and information literacy in secondary education: Mapping and visualization of trends and concepts. Scientometrics 2019, 118, 479-498. [CrossRef]

12. Van-Eck, N.J.; Waltman, L.R. VOSviewer: A computer program for bibliometric mapping. Soc. Sci. Electron Publ. 2009, 84, 523-538.

13. Chen, C.M. CiteSpace II: Detecting and visualizing emerging trends and transient patterns in scientific literature. J. Am. Soc. Inf. Sci. Technol. 2006, 57, 359-377. [CrossRef]

14. Chen, C.M.; Hu, Z.G.; Liu, S.B.; Tseng, H. Emerging trends in regenerative medicine: A scientometric analysis in CiteSpace. Expert Opin. Biol. Ther. 2012, 12, 593-608. [CrossRef]

15. Chen, C.M. Science mapping: A systematic review of the literature. J. Data Inf. Sci. 2017, 2, 1-40. [CrossRef]

16. Eck, N.J.V.; Waltman, L. Citnetexplorer: A new software tool for analyzing and visualizing citation networks. J. Inf. 2014, 8, 802-823.

17. Lu, Y.; Li, Z.; Arthur, D. Mapping publication status and exploring hotspots in a research field: Chronic disease self-management. J. Adv. Nurs. 2014, 70, 1837-1844. [CrossRef]

18. Zhao, F.K.; Shi, B.; Liu, R.X.; Zhou, W.K.; Shi, D.; Zhang, J.S. Theme trends and knowledge structure on choroidal neovascularization: A quantitative and co-word analysis. BMC Ophthalmol. 2018, 18, 86. [CrossRef]

19. Qaiser, F.H.; Ahmed, K.; Sykora, M.; Choudhary, A.; Simpson, M. Decision support systems for sustainable logistics: A review and bibliometric analysis. Ind. Manag. Data Syst. 2017, 117, 1376-1388. [CrossRef]

20. Tian, X.; Geng, Y.; Zhong, S.Z.; Wilson, J.; Gao, C.X.; Chen, W.; Yu, Z.J.; Hao, H. A bibliometric analysis on trends and characters of carbon emissions from transport sector. Transp. Res. D Transp. Environ. 2018, 59, 1-10. [CrossRef]

21. Cobo, M.J.; Lopez-Herrera, A.G.; Herrera-Viedma, E.; Herrera, F. Science mapping software tools: Review, analysis, and cooperative sudy among tools. J. Am. Soc. Inf. Sci. Technol. 2011, 62, 1382-1402. [CrossRef]

22. Wang, X.X.; Xu, Z.S.; Share, M. A bibliometric analysis of Economic Research-Ekonomska Istrazivanja (2007-2019). Ekono. Istraz. 2020, 33, 865-886. [CrossRef] 
23. Xu, Z.S.; Zhou, W.; Baltrenaite, E. Comprehensive bibliometric study of journal of environmental engineering and landscape management from 2007 to 2019. J. Environ. Eng. Landsc. 2019, 27, 215-227. [CrossRef]

24. Pilkington, A.; Meredith, J. The evolution of the intellectual structure of operations management-1980-2006: A citation/co-citation analysis. J. Oper. Manag. 2009, 27, 185-202. [CrossRef]

25. Hirsch, J.E. An index to quantify an individual's scientific research output. Proc. Natl. Acad. Sci. USA 2005, 102, 16569-16572. [CrossRef] [PubMed]

26. Graham, J.H.; Raz, S.; Hel-Or, H.; Nevo, E. Fluctuating asymmetry: Methods, theory, and applications. Symmetry 2010, 2, 466-540. [CrossRef]

27. Bamba, K.; Odintsov, S.D. Inflationary cosmology in modified gravity theories. Symmetry 2015, 7, 220-240. [CrossRef]

28. Klingenberg, C.P. Analyzing fluctuating asymmetry with geometric morphometrics: Concepts, methods, and applications. Symmetry 2015, 7, 843-934. [CrossRef]

29. Kleinberg, J. Bursty and hierarchical structure in streams. Data Min. Knowl. Discov. 2003, 7, $373-397$. [CrossRef]

30. Zadeh, L.A. Fuzzy sets. Inf. Control 1965, 8, 338. [CrossRef]

31. Ding, Y.; Gobinda, G.C.; Schubert, F. Bibliometric cartography of information retrieval research by using co-word analysis. Inf. Process Manag. 2001, 37, 817-842. [CrossRef]

32. Su, H.; Lee, P.C. Mapping knowledge structure by keyword cooccurrence: A first look at journal papers in Technology Foresight. Scientometrics 2010, 85, 65-79. [CrossRef]

(C) 2020 by the authors. Licensee MDPI, Basel, Switzerland. This article is an open access article distributed under the terms and conditions of the Creative Commons Attribution (CC BY) license (http://creativecommons.org/licenses/by/4.0/). 